\title{
About the Authors
}

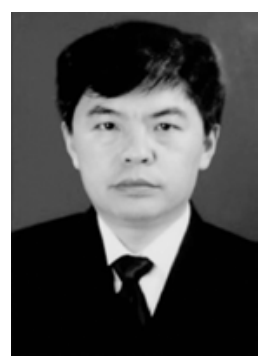

Born in Pengxi County, Sichuan Province, in April, 1963, Li Jianjun graduated from Beijing Institute of Technology (BIT) and received his Ph.D. degree in engineering in 1995. As a researcher, he enjoys the State Council's special allowance. He was the Representative of Thirteenth Guangzhou Municipal People's Congress, the Vice Chairman, General Manager of Kingfa Scientific and Technological Co., Ltd. He has successive granted titles including "Model Worker of Guangdong Province," "Guangdong Provincial Labor Medal" and "The Labor Model of Guangzhou," and so on and also won two Second National Science and Technology Progress Prizes and various awards for inventions and patents of Science and Technology Progress Award in Guangzhou, Guangdong Province. He was the council member of the of "Chinese Engineering Science;" the editorial board member of magazine "Plastic," Vice Chairman of China Association for Promotion of Private Sci-Tech Enterprises; the incumbent Vice President of China Plastics Processing Industry Association; Chairman of Multifunctional Master Batch Professional Committee; member of the National Technical Committee for Standardization of Plastics; Executive Deputy Director of Modified Plastics SubTechnical Committee of the National Technical Committee for Standardization; and adjunct professor of Beijing Institute of Technology, Sun Yat-sen University, Southwest University of Science and Technology. He has written and translated six books including The Plastics of Flame Retardancy of Styrene Plastics, Flame-Retardant Performance Manufacturing and Application, The Test Methods of the Performance of Flame Retardance of Materials, Flame-Retardant Plastics Handbook, The Nanocomposites of Flame Retardant Polymers and Plastics Additives Handbook. What's more, he has published 28 academic papers.

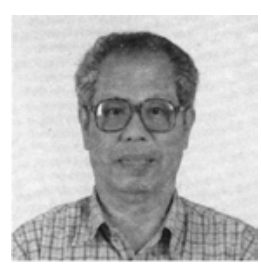

Born in February 1936 in Ji'an, Jiangxi Province, Ou Yuxiang graduated from Department of Chemical Engineering of Beijing Industrial Institute (BIT) in 1959. He engaged in physical organic chemistry research in both Britain and the United States during 1979-1982. He was the former Chief Professor of Ph.D. programs of Materials Science of Beijing Institute of Technology, the Chairman of Institute of Flame Retardant of China, and a famous expert in the areas of energetic materials and fire-retardant materials. He has long been committed to the researches of energetic materials and flame-retardant materials and published more than 20 books and over 300 papers, collected the parts of energetic materials and fire-retardant materials in various large-scale encyclopedias and dictionaries and edited relevant proceedings of international conference 7 times. His representative works include Practical Flame Retardant Technology, Polymer Materials of Flame Retardant, The Test Methods of the Performance of Flame Retardance of Materials, Flame Retardant, and so on. He was the first inventor to hold the first position in the Progress Award of National Defense Science and Technology, Petrochemical Industry Excellent Book Award and other awards and obtained seven National Invention Patents. As a doctoral tutor, he has polished nearly 30 doctoral students. Since 1992, he has enjoyed special government allowance. He was recommended twice as the effective candidate of The Chinese Academy of Engineering in 2003 and 2005. In 2001, he was also included into the World's Outstanding Scientists List by the International Biographical Centre. In June 2007, China Chemical Industry News published a special report for his outstanding contribution to Chinese flame-retardant science and technology under the title "The Founder of Chinese Flame Retardant Science." 
